\title{
EFFECT OF REPRESSING ON THE COLOR AND TRANSLUENCY OF LITHIUM DISILICATE PRESSABLE CERAMIC MATERIAL
}

\author{
Yara M. Elnaggar, $B D S,{ }^{1}$ Ihab A. Hammad, BDS, MS, ${ }^{p} s c{ }^{2}{ }^{2}$ Amir Azer, BDS, MS, $P h D^{3}$
}

ABSTRACT

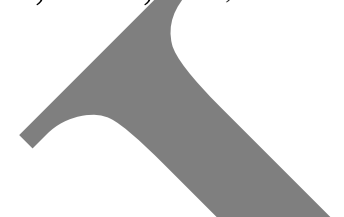

INTRODUCTION: outcome. Color parameters is one of the major influencers for the esthetic outcome which is affected by different factors such as chemical composition and thickness. In clinical practice, pressable ceramics were found to be frequently subjected to repressing. Nonetheless, the effect of the repressing on the color stability and translucency have been unknown.

OBJECTIVES: The aim of this study was to investigate the effect of repressing on the color and translucency of a lithium disilicate pressable ceramic material (e.max press).

MATERIALS AND METHODS: twenty-four disc-shaped ceramic specimens (IPS e.max press ingots) 14 mm in diameter and 1.5 mm thick were divided into two parallel groups: press group and repress group. Each group had 12 specimens. Pressing was performed for e.max press ingots. Repressing was performed using the remaining material resulting from the pressing procedure. Color difference and translucency were measured using a portable spectrophotometer (VITA easy shade Advance). Translucency parameter (TP) was measured on black and white backgrounds. The resultant data were analyzed statistically using Kruskal-Wallis non-parametric test.

RESULTS: There was a statistically significant difference in color change after repressing. ( $\mathrm{p}=0.005)$. e.max pressed group produced color difference $(\Delta \mathrm{E})$ values of $(3.88 \pm 1.12)$. This $(\Delta \mathrm{E})$ values was more than the selected clinical perceptible threshold selected for this study $(\Delta \mathrm{E}=2.6)$. Moreover, e.max pressed group showed statistically significant decrease in translucency after repressing $(\mathrm{p}=0.002)$.

CONCLUSIONS: The color of e.max press was affected by repressing with statistically significant decrease in translucency. KEYWORDS: repressing, e.max, color, translucency, pressable ceramics, spectrophotometer.

1 Instructor of Fixed Prosthodontics, Department of Conservative Dentistry, Alexandria University, Alexandria, Egypt

2 Professor of Fixed Prosthodontics and former Dean, Department of Conservative Dentistry, Alexandria University, Alexandria, Egypt

3 Lecturer of Fixed Prosthodontics, Department of Conservative Dentistry, Alexandria University, Alexandria, Egypt

*Corresponding author yara.elnaggar13@gmail.com

\section{INTRODUCTION}

The individual's appearance has recently become one of the major concerns in life. Patient demand for esthetic dentistry is steadily growing because teeth affect both general health and self-esteem. Ceramic materials are the most natural-appearing replacement material for missing tooth structure. Ceramics can be processed by several techniques: casting, pressing, machining, or the traditional powder and liquid mixing $(1,2)$.

Pressable ceramics is supplied in an ingot form. These ingots are melted at high temperatures then pressed into a mold created by the lost-wax technique under pressure from pneumatic press furnaces (1-3).

Lithium disilicate glass ceramics are based on SiO2$\mathrm{Li} 2 \mathrm{O}$ system. This glass ceramic is so widespread because of their relative translucency, high strength and can be monolithic. It also displays high mechanical properties, flexural strength (350- $450 \mathrm{MPa}$ ) and fracture toughness (14). A recent study in 2016 claimed that IPS e.max Press is superior to IPS e.max CAD regarding the fracture toughness (5).

IPS e.max Press is broadly spread in the dental field. It shows high mechanical properties which permits fabrication of crowns on the anterior and posterior teeth. It also displays reasonable translucency to be used with satisfaction in the anterior region (6). In 2017, a study showed that IPS e.max press can be used as an ocular prosthesis scleral veneer due to its high translucency and excellent mechanical properties (7).

After pressing the ceramic ingots under heat and pressure, the remaining material of the ingot are frequently removed then rejected. It has been informed that in some dental laboratories these buttons are reused. So, the question is what will be the effect of this repressing procedure on the mechanical properties of these materials.

Previous studies by Albakry (8) and Raigrodski et al (9) demonstrated that repressing did not influence the flexural strength of pressable ceramics. However, there is lack of information regarding the effect of repressing on color 
stability and translucency of ceramics. The purpose of the present study was to assess the influence of repressing on the color stability and translucency of a pressable glass ceramics; IPS e.max Press. The null hypothesis is that there will be no change in the color and translucency of e.max press after repressing.

\section{MATERIALS AND METHODS}

A total of twenty-four-disc shape specimens were constructed. IPS e.max Press (Ivoclar Vivadent). was used to create disc specimens of $14 \mathrm{~mm}$ diameter and $1.5 \mathrm{~mm}$ thickness ( $\mathrm{n}=12$ per group).

Initially, 24-disc shaped wax specimens (Dental wax, Schuler-Dental, Gmbh \& Co, Germany) were made-up with the required diameter using CAD-CAM (Ceramill Motion 2, Amann girrbach AG, Austria). Afterwards, these wax specimens were sprued and attached to the base former and enclosed by the silicone ring. Subsequently, investment material was mixed according to the manufacturer's instructions on a vibrator to prevent the formation of air bubbles then it was poured into the ring. After complete setting of the investment material, the ring was inserted inside a burn-out furnace (BEGO GmbH \& Co, Germany). The heat of the furnace was regularly increased till $850^{\circ} \mathrm{C}$. As soon as the temperature reached $850^{\circ} \mathrm{C}$, the ring was inverted upside down and the temperature was maintained for extra 10 minutes to ensure complete burn-out.

Heat pressing process was performed according to the manufacturer's instructions. After pressing and complete cooling of the ring was accomplished, the specimens were carefully devested. This pressed group is the control group $(n=12)$. The sprues and the remaining buttons were separated from the specimens using a diamond cutting disc and customized by grinding to allow proper insertion into the molds for repressing. The same procedures of wax specimen's construction, spruing, investing, heat pressing, and divesting were performed to press these buttons. This repressed group is the test group $(n=12)$. The final thickness of each specimen was measured using digital micrometer. Lastly, the 24 pressed and repressed specimens were finished according to the manufacturer's instructions.

Color parameters of pressed and repressed specimens were measured using digital spectrophotometer (Vita Easyshade Advance, VITA Zahnfabrik, Germany) over a black background (10). Calibration for the spectrophotometer had to be done before color measurements of each group.

Color parameters were expressed in terms of the three coordinate values $\left(L^{*}, a^{*}, b^{*}\right)$, which were established by the Commission International de l'Eclairage (CIE) in 1976. Color difference $(\Delta \mathrm{E})$ between pressed and repressed groups was calculated by the following formula (11):

$\Delta \mathrm{E}=\left[\left(\Delta \mathrm{L}^{*}\right)^{2}+\left(\Delta \mathrm{a}^{*}\right)^{2}+\left(\Delta \mathrm{b}^{*}\right)^{2}\right]^{1 / 2}$

$\Delta \mathrm{L}^{*}, \Delta \mathrm{a}^{*}$, and $\Delta \mathrm{b}^{*}$ represent the difference in CIE color-space parameters of the two specimens. $(\Delta \mathrm{E})$ of 2.6 or less was considered clinically acceptable in the study.
The translucency parameter (TP) was obtained by calculating the color difference between the specimens over a black background and that over a white background by the following formula:

$$
\mathrm{TP}=\left[\left(\mathrm{L}^{*}{ }_{\mathrm{B}}-\mathrm{L}^{*} \mathrm{w}\right)^{2}+\left(\mathrm{a}^{*}{ }_{\mathrm{B}}-\mathrm{a}^{*} \mathrm{w}\right)^{2}+\left(\mathrm{b}^{*}{ }_{\mathrm{B}}-\mathrm{b}^{*} \mathrm{w}\right)^{2}\right]^{1 / 2}
$$

Where ' $\mathrm{B}$ ' refers to the color coordinates over a black background and ' $\mathrm{W}$ ' refers to those over a white background.

\section{STATISTICAL ANALYSIS}

Statistical analysis was performed using SPSS statistic version 20.0 software. The resultant data were analyzed statistically using Kruskal-Wallis non-parametric test. All variables showed non-normal distribution, so mean, Standard Deviation (SD), median and interquartile range (IQR) were calculated. Significance was set at $\mathrm{P}<0.05$.

\section{RESULTS}

The Mean \pm Std. Deviation of the color parameters of both pressed and repressed groups, as well as a 95\% confidence interval of the mean, are shown in (table 1). According to the Kruskal-Wallis non-parametric test, there was a significant difference in color between the two groups $(\mathrm{p}=0.005)$.

The results of the present study showed changes in the 3 coordinate values of the color parameters $\left(L^{*}, a^{*}, b^{*}\right)$ after repressing. The mean value of $\mathrm{L}^{*}$ coordinate was decreased from $(80.2 \pm 0.8)$ to $(78.04 \pm 0.8)$. Regarding $a^{*}$ coordinate, the mean value increased from $(-0.18 \pm 0.14)$ to $(0.210 \pm 0.33)$ after repressing. Concerning the $\mathrm{b}^{*}$ coordinate, the mean value decreased from $(19.55 \pm 0.65)$ to $(16.79 \pm 0.82)$. After repressing, e.max Press group yielded $(\Delta \mathrm{E})$ mean values of $(3.88 \pm 1.12)$. This $(\Delta \mathrm{E})$ mean values are beyond the selected clinical perceptible threshold $(\Delta \mathrm{E}=2.6)$.

Table 1: Color difference between pressed and repressed groups

\begin{tabular}{|c|c|c|}
\hline $\begin{array}{c}\text { E-Max Press vs } \\
\text { Repress }\end{array}$ & $\begin{array}{c}\text { Black } \\
\text { Background }\end{array}$ & $\begin{array}{c}\text { Test of significance } \\
\boldsymbol{p} \text { value }\end{array}$ \\
\hline$-\quad \mathrm{n}$ & 12 & \\
$-\quad$ Min- & $2.0020-6.8864$ & \\
$-\quad$ Mean \pm & $3.8815 \pm 1.1174$ & $\mathrm{Z}_{(\mathrm{KW})}=3.897$ \\
Std. Deviation & $4.076145-$ & $\mathrm{p}=0.000^{*}$ \\
$-\quad$ 95\% CI & 3.8769259 & \\
for mean & $4.7878)$ & \\
- Median & $\mathrm{D}=0.174$, & \\
(IQR) & $\mathrm{p}=0.200 \mathrm{NS}$ & \\
KS test & & \\
of normality & & \\
\hline
\end{tabular}

$\mathrm{n}$ : Number of specimens

Min-Max: Minimum - Maximum

KS: Kolmogorov-Smirnov

$\mathrm{KW}$ : Kruskal-Wallis test

*: Statistically significant $(\mathrm{p}<0.05)$

NS: Statistically not significant $(\mathrm{p} \geq 0.05)$ 
Regarding the translucency parameter (TP), the statistical data is summarized in (table 2) in which e.max press showed statistically significant decrease in translucency after repeated pressing $(\mathrm{p}=0.002)$.

Table 2: Difference between pressed and repressed groups in translucency

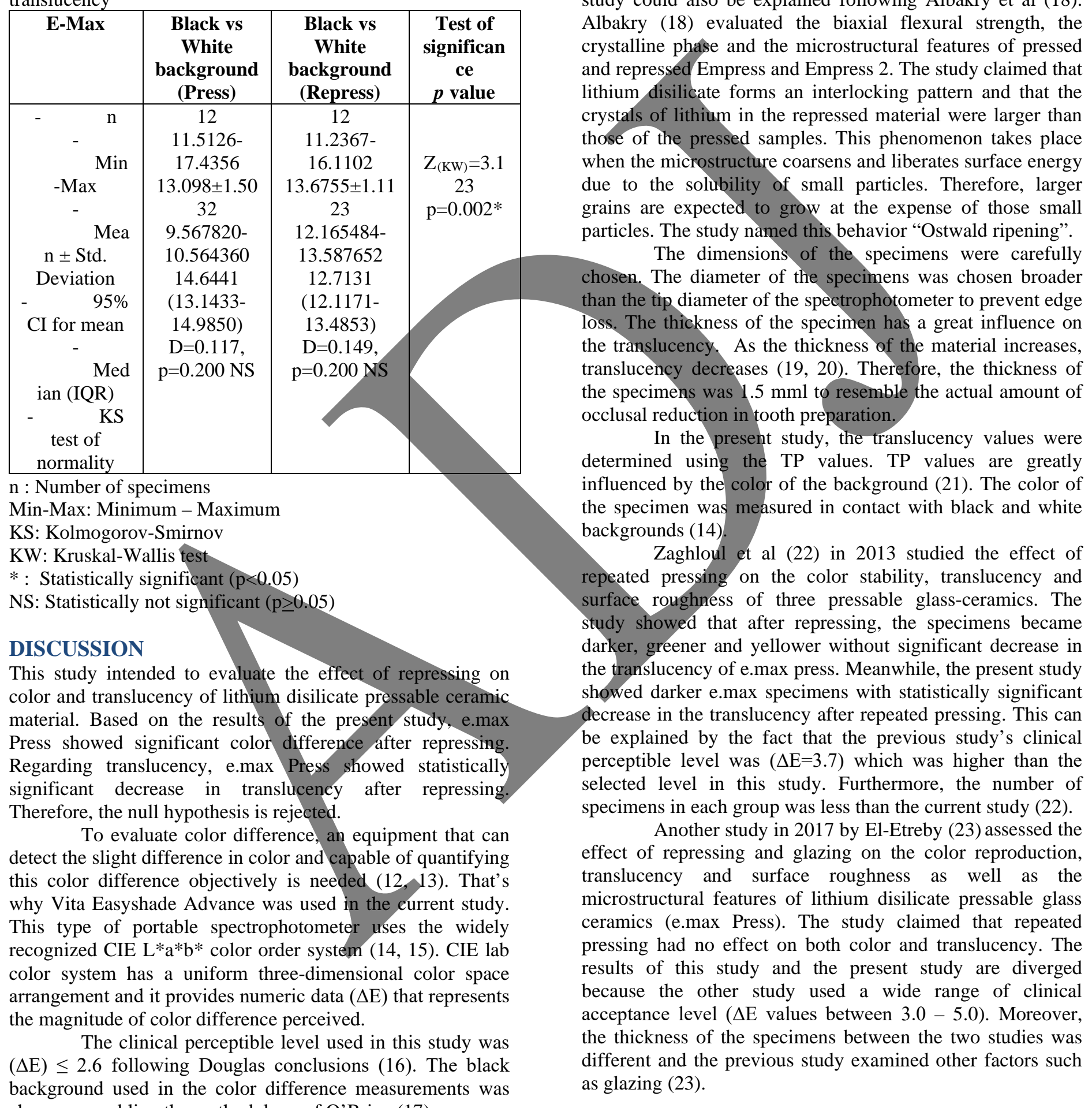

According to the changes occurred to the 3 coordinates $\left(\mathrm{L}^{*}, \mathrm{a}^{*}, \mathrm{~b}^{*}\right)$, the repressed specimens were found to be darker, reddish and bluish than the pressed samples which clarifies the color difference existed between the two groups.

The color difference that resulted in the present study could also be explained following Albakry et al (18). Albakry (18) evaluated the biaxial flexural strength, the crystalline phase and the microstructural features of pressed and repressed Empress and Empress 2. The study claimed that lithium disilicate forms an interlocking pattern and that the crystals of lithium in the repressed material were larger than those of the pressed samples. This phenomenon takes place when the microstructure coarsens and liberates surface energy due to the solubility of small particles. Therefore, larger grains are expected to grow at the expense of those small particles. The study named this behavior "Ostwald ripening”.

The dimensions of the specimens were carefully chosen. The diameter of the specimens was chosen broader than the tip diameter of the spectrophotometer to prevent edge loss. The thickness of the specimen has a great influence on the translucency. As the thickness of the material increases, translucency decreases $(19,20)$. Therefore, the thickness of the specimens was $1.5 \mathrm{mml}$ to resemble the actual amount of In the present study, the translucency values were determined using the TP values. TP values are greatly influenced by the color of the background (21). The color of the specimen was measured in contact with black and white backgrounds (14)

Zaghloul et al (22) in 2013 studied the effect of epeated pressing on the color stability, translucency and surface roughness of three pressable glass-ceramics. The study showed that after repressing, the specimens became darker, greener and yellower without significant decrease in the translucency of e.max press. Meanwhile, the present study showed darker e.max specimens with statistically significant decrease in the translucency after repeated pressing. This can perceptible level was $(\Delta \mathrm{E}=3.7)$ which was higher than the selected level in this study. Furthermore, the number of specimens in each group was less than the current study (22). effect of repressing and glazing on the color reproduction, translucency and surface roughness as well as the microstructural features of lithium disilicate pressable glass ceramics (e.max Press). The study claimed that repeated pressing had no effect on both color and translucency. The results of this study and the present study are diverged because the other study used a wide range of clinica the thickness of the specimens between the two studies was different and the previous study examined other factors such CONCLUSIONS 
Within the limitations of the present study, it was concluded that repressing IPS e.max resulted in a significant color difference which was beyond the clinical perceptible threshold $(\Delta \mathrm{E}) 2.6$ selected in the study. Moreover, repressing IPS e.max press resulted in a significant translucency changes.

\section{CONFLICT OF INTERESTS}

The authors declare that they have no conflict of interest.

\section{REFERENCES}

1- Shenoy A, Shenoy N. Dental ceramics: An update. J Conserv Dent. 2010;13:195-203.

2- Narasimha RR. Ceramics in Dentistry. In: Lakshmanan A, ed. Sintering of Ceramics - New Emerging Techniques. Vienna, Austria: IntechOpen; 2012:203-26.

3- Ansong R, Flinn B, Chung KH, Mancl L, Ishibe M, Raigrodski AJ. Fracture toughness of heat-pressed and layered ceramics. J Prosthet Dent. 2013;109: 234-40.

4- Denry I, Holloway JA. Ceramics for dental applications: a review. Materials. 2010;3:351-68.

5- Alkadi L, Ruse ND. Fracture toughness of two lithium disilicate dental glass ceramics. J Prosthet Dent [Internet]. 2016;116:591-6.

6- Conrad HJ, Seong WJ, Pesun IJ. Current ceramic materials and systems with clinical recommendations: A systematic review. J Prosthet Dent. 2007;98:389-404.

7- Da Costa GC, Aras MA, Chalakkal P, Da Costa MC. Ocular prosthesis incorporating IPS e-max press scleral veneer and a literature review on non-integrated ocular prosthesis. Int J Ophthalmol. 2017;10:148-56.

8- Albakry M, Guazzato M, Swain MV. Biaxial flexural strength and microstructure changes of two recycled pressable glass ceramics. J Prosthet Dent. 2004;13:141-9.

9- Raigrodski AJ, Chiche GJ, Potiket N, Hochstedler JL, Mohamed SE, Billiot S, et.al. The efficiency of posterior three-unit zirconia -oxide-based ceramic fixed partial dental prostheses: a prospective clinical pilot study. J Prosthet Dent. 2006;96:237-44.

10-Chu FCS, Chow TW, Chai J. Contrast ratios and masking ability of three types of ceramic veneers. J Prosthet Dent 2007;98:359-64.
11-Vichi A, Louca C, Corciolani G, Ferrari M. Color related to ceramic and zirconia restorations: A review. Dent Mater. 2011;27:97-108.

12-Douglas RD, Steinhauer TJ, Wee AG. Intraoral determination of the tolerance of dentists for perceptibility and acceptability of shade mismatch. J Prosthet Dent. 2007;97:200-8.

13-Hammad IA. Intrarater repeatability of shade selections with two shade guides. J Prosthet Dent. 2003;89:50-3.

14-Heydecke G, Zhang F, Razzoog ME. In vitro color stability of double-layer veneers after accelerated aging. J Prosthet Dent. 2001;85:551-7.

15- Knezović D, Zlatarić $\mathrm{D}$, Illeš IZ, Alajbeg M, Žagar. In Vivo and in Vitro Evaluations of Repeatability and Accuracy of VITA Easyshade ${ }^{\circledR}$ Advance 4.0 Dental Shade-Matching Device. Acta Stomatol Croat. 2015;49: 112-18.

16-Niu E, Agustin $M$, Douglas RD. color match of machinable lithium disilicate ceramics: effects of cement color and thickness. J prosthet dent. 2014;111:42-50.

17-O’Brien WJ, Groh CL, Boenke KM. A New, Small-colordifference Equation for Dental Shades. J Dent Research.1990;69:1762-4.

18-Albakry M, Guazzato M, Swain MV. Biaxial flexural strength and microstructure changes of two recycled pressable glass ceramics. J Prosthet Dent. 2004;13:141-9.

19-Heffernan MJ, Aquilino SA, Diaz-Arnold AM, Haselton DR, Stamford CM, Vargas MA. Relative translucency of six all-ceramic systems. Part I: Core materials. J Prosthet Dent. 2002;88:4-9.

20-Johnston WM, O'Brien WJ, Tien TY. The determination of optical absorption and scattering in translucent porcelain. Color Res Appl. 1986;11:125-30.

21-Johnston WM, Reisbick MH. Color and translucency changes during and after curing of esthetic restorative materials. Dent Mater. 1997;13: 89-97.

22-Zaghloul H, Halim C, Ghanim LA. Effect of repeated heat pressing on color, translucency and surface quality of pressable ceramics. E.D.J. 2013;59:2913-31.

23-El-Etreby AS. Effect of repressing and glazing on color reproduction, translucency and surface roughness of lithium disilicate glass-ceramics. E.D.J. 2017;63:79-88. 